\title{
Care-engaged individuals with polysubstance use in Northeastern US are undertreated for methamphetamine use disorder: a retrospective cohort study
}

\author{
Mimi Yen Li ${ }^{1}$, George A. Alba ${ }^{1,3}$, Julian Mitton ${ }^{2+}$ and Benjamin Bearnot ${ }^{1,3^{*}+}$ (D)
}

\begin{abstract}
Background: Stimulant use has increased across the US, with concomitant opioid and methamphetamine use doubling between 2011 and 2017. Shifting patterns of polysubstance use have led to rising psychostimulant-involved deaths. While it is known that individuals who use methamphetamine require greater access to treatment, there is still little known about methamphetamine use and treatment among individuals who are already engaged in outpatient substance use treatment.
\end{abstract}

Objectives: To characterize care-engaged individuals who use methamphetamine to guide harm reduction and treatment strategies.

Methods: Retrospective cohort study of individuals at a large academic medical center in Massachusetts with $\geq 2$ positive methamphetamine oral fluid toxicology tests between August 2019 and January 2020. We performed descriptive analysis of sociodemographic, medical, and drug use characteristics and a comparative analysis of injection methamphetamine use versus other routes of use.

Results: Included were 71 individuals [56 male (80\%), 66 non-Hispanic white (94\%), median age 36 (IQR 30-42)]. Nearly all had opioid (94\%) and stimulant use disorder (92\%). Most had (93\%) or were (83\%) being treated with medications for opioid use disorder, but few received pharmacologic treatment for methamphetamine use disorder (24\%). None received contingency management treatment.

People who inject methamphetamine (68\%) were more likely to have a history of overdose (91\% vs. 70\%; $p=0.02$ ), have HCV (94\% vs. 52\%; $p<0.01)$, use fentanyl $(93 \%$ vs. $65 \% ; p=0.02)$, and engage in sex work (19\% vs. 0\%; $p=0.03)$ compared to those who used via other routes. Both groups had prevalent homelessness ( $88 \%$ vs. $73 \% ; p=0.15$ ), incarceration ( $81 \%$ vs. $64 \% ; p=0.11$ ), depression ( $94 \%$ vs. $87 \% ; p=0.34$ ), and bacteremia ( $27 \%$ vs. $22 \% ; p=0.63$ ).

Conclusions: Individuals in our study had high prevalence of polysubstance use, particularly concomitant methamphetamine and opioid use. Individuals who were well connected to substance use treatment for their opioid use were still likely to be undertreated for their methamphetamine use disorder and would benefit from greater access

\footnotetext{
*Correspondence: bbearnot@mgh.harvard.edu

†Benjamin Bearnot and Julian Mitton contributed equally to this manuscript

${ }^{3}$ Department of Medicine, Massachusetts General Hospital, 100 Cambridge Street, Suite 1600, Boston, MA 02114, United States

Full list of author information is available at the end of the article
} permits use, sharing, adaptation, distribution and reproduction in any medium or format, as long as you give appropriate credit to the original author(s) and the source, provide a link to the Creative Commons licence, and indicate if changes were made. The images or other third party material in this article are included in the article's Creative Commons licence, unless indicated otherwise in a credit line to the material. If material is not included in the article's Creative Commons licence and your intended use is not permitted by statutory regulation or exceeds the permitted use, you will need to obtain permission directly from the copyright holder. To view a copy of this licence, visit http://creativecommons.org/licenses/by/4.0/. The Creative Commons Public Domain Dedication waiver (http://creativeco mmons.org/publicdomain/zero/1.0/) applies to the data made available in this article, unless otherwise stated in a credit line to the data. 
to contingency management treatment, harm reduction resources, and resources to address adverse social determinants of health.

Keywords: Methamphetamine, Opioid crisis, Harm reduction, Stimulants, Drug overdose

\section{Introduction}

Stimulant use has escalated in the United States (US), following three earlier waves of prescription opioid, heroin, and fentanyl use, to forge a fourth wave of the opioid crisis [1-3]. A rise in amphetamine-related serious bacterial infections and hospitalizations has contributed to a nearly five-fold increase in amphetamine-related hospital costs $[4,5]$. Overdose deaths associated with amphetamine-type stimulants have increased approximately $30 \%$ per year between 2012 and 2018, with methamphetamine accounting for $11 \%$ of the total number of US overdose deaths in 2011 [6]-[9]. The doubling of concomitant opioid and methamphetamine use between 2011 and 2017 suggest the rise of methamphetamine is connected to, not separate from, the opioid crisis [1]. Convergence of the opioid and methamphetamine crises poses particular risks in the Northeastern US, where opioids such as fentanyl, heroin, and oxycodone are among the top five most common drugs involved in overdoses [10]. Dynamic changes in drug hotspot patterns already suggest methamphetamine use, which have historically predominated in the Western US, is no longer a regional issue [11]. From 2008 to 2017, primary heroin treatment admissions involving methamphetamine use increased in all US geographic regions, with a thirteen-fold increase in the Northeast [12]. Rising concomitant methamphetamine use has led to treatment challenges as individuals who use methamphetamine are less likely to be retained in opioid use treatment [13]. In 2015, 36\% of opioid-related overdoses in Massachusetts involved stimulants [9]. From 2018 to 2019, the largest relative increase in the psychostimulant-involved death rate occurred in the Northeast (44\%) [14]. Emergency departments and outpatient settings in the Northeast have also begun to see a rise in methamphetamine use in patients $[8,15]$.

However, there is limited characterization of individuals who use methamphetamine in the Northeastern US, and particularly for subpopulations who use methamphetamine via injection, which has been correlated with higher prevalence of infectious disease, psychiatric conditions, and adverse social determinants of health [1618]. Moreover, while a number of studies highlighting the medical and social complexity of individuals who use methamphetamine call for greater access to treatment, there is little known about methamphetamine use and treatment among individuals who are already engaged in outpatient substance use treatment [19-21]. There are currently no FDA-approved pharmacologic therapies for methamphetamine use disorder (MUD), though there have been single and multisite clinical trials conducted for a range of pharmacologic agents including antidepressants, anticonvulsants, stimulants and opioid antagonists $[22,23]$. The behavioral therapy with the strongest evidence for MUD treatment is contingency management, a behavioral treatment that takes advantage of operant conditioning to promote therapeutic behaviors. It involves the provision of positive reinforcements, such as money or gift cards, for target behaviors such as drug abstinence. Multiple randomized controlled trials have demonstrated the efficacy of contingency management in reducing methamphetamine use and increasing treatment retention [24-27]. However, contingency management is not widely available and generally underutilized as a treatment [28]. Engagement in contingency management therapy is unknown for individuals with polysubstance use who are connected to care. Greater understanding of the specific needs of care-engaged individuals who use methamphetamine is necessary to guide harm reduction and effective treatment strategies.

This study aimed to characterize care-engaged individuals who use methamphetamine at a large academic medical center in Boston, Massachusetts across multiple social and medical domains. Following characterization of the cohort, we further sought to examine characteristics associated with injection methamphetamine use.

\section{Methods \\ Study design and population}

We performed a retrospective electronic medical record (EMR) review of patients at a large academic medical center in Boston, Massachusetts (48,000 admissions and $5,00,000$ primary care visits annually) with $\geq 2$ positive methamphetamine oral toxicology tests between August 1, 2019 and January 31, 2020. Oral fluid toxicology tests, conducted via liquid chromatography-tandem mass spectrometry, are highly specific for methamphetamines with a low likelihood of false positives [29]. We included all individuals with $\geq 2$ positive methamphetamine oral toxicology tests to further increase specificity for individuals using methamphetamines more regularly [30]. We considered this patient population "care-engaged" as they receive integrated ambulatory and addiction care from the large health system through a combination of community health centers, primary care practices, infectious 
disease clinics, a low-threshold transitional addiction clinic, and peer recovery support. Medical records were reviewed and coded using information available up to July 1, 2020 to allow for a reasonable duration of medical follow up time for participants.

A list of data elements was created and refined iteratively (BB, JM). A data extraction instrument was then developed using REDCap (REDCap, Version 9.5.35) (BB, JM) [31]. Free text search terms and a search algorithm were appended to the REDCap instrument to standardize use between researchers (BB, JM).

Chart reviews were conducted between July 1 and September 1,2020 , using standardized terms to query the EMR via the free text search functionality (MYL). Areas of uncertainty were adjudicated between team members. Missing data points were included in the analysis and treated as missing at random. Following an initial review of all participant medical records, a $20 \%$ random sample was reviewed by a different team member, to reconcile inter-coder differences and check for missing data. Minor changes were made to the data instrument and all participants reviewed again to ensure fidelity to the updated instrument.

\section{Exposure and outcome definitions}

We examined the sociodemographic, medical history and treatment, drug use, and high-risk behavior characteristics of study participants. Participants were assessed for lifetime history of characteristics unless otherwise specified.

Sociodemographic characteristics included: age, sex, sexual behavior, race/ethnicity, education, marital status, and lifetime history of homelessness and incarceration.

Medical characteristics included: substance use disorder (SUD) history including opioid, stimulant, benzodiazepine, alcohol, and hallucinogen use disorder; history of overdose from any drug; infection history including endocarditis, osteomyelitis, septic arthritis, superficial abscess, paraspinal abscess, and bacteremia; history of Hepatitis C virus; history of HIV; and psychiatric history including psychosis, depression, and suicidal ideation or attempt. An individual was considered to have a history of substance use if use was documented in $\geq 1$ note, and considered to have a history of a SUD if explicit documentation of SUD appeared in $\geq 1$ note or under an ICD10-CM code.

Medical care characteristics included MUD treatment defined as contingency management or prescriptions for bupropion, naltrexone, rivastigmine, topiramate, modafinil, mirtazapine, or stimulant medications with an explicit indication for harm reduction or MUD treatment; past and current opioid use disorder (OUD) treatment including methadone, buprenorphine, and naltrexone; recent prescriptions of controlled substances written between 2019 and 2020; prescriptions of naloxone or pre-exposure prophylaxis for HIV prevention; and engagement in addiction specialty services including low-barrier-to-entry Bridge clinic, addiction psychiatry, a buprenorphine-prescribing primary care physician, office-based addiction treatment nurse, or recovery coach.

Drug use behaviors including route of methamphetamine use (injection, smoking, snorting, other) and highrisk behaviors (sex work and needle sharing) were also assessed.

\section{Statistical analysis}

The overall prevalence of sociodemographic and medical characteristics were calculated for all participants. Participants were then stratified into two groups by their route of methamphetamine use: individuals who indicated methamphetamine use by injection and individuals who indicated methamphetamine use via smoking, snorting or other means. The groups were then compared across all variables via chi-square tests for categorical variables and Fisher's Exact tests for continuous variables in STATA (version 16.1, STATACorp, College Station, TX), using a p value cut off of 0.05 for significant findings.

This study was approved by the Mass General Brigham Institutional Review Board.

\section{Results}

\section{Sociodemographics}

A total of 71 individuals had $\geq 2$ positive oral toxicology tests between August 1, 2019 and January 1, 2020 and were included in this analysis (Table 1). The majority were male (80\%), 66 non-Hispanic white (94\%), and the median age was 36 (IQR $=30-42)$ ]. Approximately $21 \%$ were males with documented history of sex with other males. A little under half (40\%) graduated from high school while $12 \%$ graduated from college. Most were single (75\%). Experiences of homelessness (83\%) and incarceration (76\%) were extremely prevalent.

\section{Medical and psychiatric co-morbidities}

Participants had high prevalence of comorbid SUD including OUD (94\%), stimulant use disorder (92\%), alcohol use disorder (42\%), and benzodiazepine use disorder (41\%). The majority (84\%) had experienced a non-lethal drug overdose. They had extensive histories of infections including Hepatitis C virus (HCV) (80\%), superficial abscesses (68\%), bacteremia (25\%), endocarditis (14\%), HIV (11\%), osteomyelitis (11\%), septic arthritis (7\%), and paraspinal abscesses (4\%). Co-occurring psychiatric conditions including depression (92\%), suicidality (58\%), and psychosis $(43 \%)$ were common. 
Table 1 Characteristics of individuals using methamphetamine with and without evidence of injection methamphetamine use

\begin{tabular}{|c|c|c|c|c|}
\hline & $\begin{array}{l}\text { All participants } \\
\mathrm{n}=71\end{array}$ & $\begin{array}{l}\text { Injection meth use } \\
n=48\end{array}$ & $\begin{array}{l}\text { No injection meth use } \\
n=23\end{array}$ & \\
\hline & No. (\%) & No. (\%) & No. (\%) & P value \\
\hline \multicolumn{5}{|l|}{ Sociodemographics } \\
\hline \multicolumn{5}{|l|}{ Age } \\
\hline $18-39$ & $49(69)$ & $35(73)$ & $14(61)$ & $\operatorname{Pr}(T<t)=0.77$ \\
\hline $40-59$ & $21(30)$ & $12(25)$ & $9(39)$ & $\operatorname{Pr}(|T|>|t|)=0.46$ \\
\hline$\geq 60$ & $1(1)$ & $0(0)$ & $0(0)$ & $\operatorname{Pr}(T>t)=0.23$ \\
\hline Sex & & & & 0.37 \\
\hline Male & $56(80)$ & $39(83)$ & $17(74)$ & \\
\hline Men who have sex with men & $14(21)$ & $10(15)$ & $4(6)$ & 0.98 \\
\hline Race/ethnicity & & & & 0.75 \\
\hline Non-Hispanic white & $66(94)$ & $45(96)$ & $21(91)$ & \\
\hline Black & $2(3)$ & $1(2)$ & $1(4)$ & \\
\hline Hispanic & $2(3)$ & $1(2)$ & $1(4)$ & \\
\hline Education & & & & 0.48 \\
\hline Some high school & $10(17)$ & $8(20)$ & $2(12)$ & \\
\hline High school graduate & $23(40)$ & $18(44)$ & $5(29)$ & \\
\hline Some college & $18(31)$ & $11(27)$ & $7(41)$ & \\
\hline College graduate & $7(12)$ & $4(10)$ & $3(18)$ & \\
\hline Marital status & & & & 0.30 \\
\hline Single & $53(75)$ & $38(79)$ & $15(65)$ & \\
\hline Married & $7(10)$ & $3(6)$ & $4(17)$ & \\
\hline Divorced/separated & $11(15)$ & $7(15)$ & $4(17)$ & \\
\hline Homelessness & $59(83)$ & $42(88)$ & $17(73)$ & 0.15 \\
\hline Incarceration & $52(76)$ & $39(81)$ & $14(64)$ & 0.11 \\
\hline \multicolumn{5}{|l|}{ Medical characteristics } \\
\hline \multicolumn{5}{|l|}{ SUD history } \\
\hline Opioid use disorder & $67(94)$ & $45(94)$ & $22(96)$ & 0.75 \\
\hline Stimulant use disorder & $65(92)$ & $47(98)$ & $18(78)$ & 0.01 \\
\hline Benzodiazepine use disorder & $29(41)$ & $25(52)$ & $4(17)$ & 0.01 \\
\hline Alcohol use disorder & $30(42)$ & $22(46)$ & $8(35)$ & 0.38 \\
\hline Hallucinogen use disorder & $1(1)$ & $1(2)$ & $0(0)$ & 0.49 \\
\hline Other & $2(3)$ & $1(2)$ & $1(4)$ & 0.59 \\
\hline History of overdose & $59(84)$ & $44(91)$ & $16(70)$ & 0.02 \\
\hline \multicolumn{5}{|l|}{ Infection history } \\
\hline Endocarditis & $10(14)$ & $9(19)$ & $1(4)$ & 0.10 \\
\hline Osteomyelitis & $8(11)$ & $6(13)$ & $2(9)$ & 0.64 \\
\hline Septic arthritis & $5(7)$ & $4(8)$ & $1(4)$ & 0.54 \\
\hline Superficial abscess & $48(68)$ & $36(75)$ & $12(52)$ & 0.05 \\
\hline Paraspinal abscess & $3(4)$ & $2(4)$ & $1(4)$ & 0.97 \\
\hline Bacteremia & $18(25)$ & $13(27)$ & $5(22)$ & 0.63 \\
\hline Other & $1(1)$ & $1(2)$ & $0(0)$ & 0.49 \\
\hline History of HCV & $57(80)$ & $45(94)$ & $12(52)$ & $<0.01$ \\
\hline History of HIV & $8(11)$ & $7(15)$ & $1(4)$ & 0.20 \\
\hline History of psychosis & $30(43)$ & $23(49)$ & $7(30)$ & 0.14 \\
\hline History of depression & $65(92)$ & $45(94)$ & $20(87)$ & 0.34 \\
\hline History of suicidal ideation/attempt & $41(58)$ & $27(56)$ & $14(61)$ & 0.71 \\
\hline \multicolumn{5}{|l|}{ Care access } \\
\hline Primary care provider (PCP) & & & & 0.09 \\
\hline PCP within our hospital system & $31(44)$ & $17(35)$ & $15(64)$ & \\
\hline PCP outside our hospital system & $34(49)$ & $26(56)$ & $7(32)$ & \\
\hline No PCP & $5(7)$ & $4(8)$ & $1(5)$ & \\
\hline MUD treatment & & & & \\
\hline
\end{tabular}


Table 1 (continued)

\begin{tabular}{|c|c|c|c|c|}
\hline & $\begin{array}{l}\text { All participants } \\
\mathrm{n}=71\end{array}$ & $\begin{array}{l}\text { Injection meth use } \\
n=48\end{array}$ & $\begin{array}{l}\text { No injection meth use } \\
n=23\end{array}$ & \\
\hline & No. (\%) & No. (\%) & No. (\%) & $P$ value \\
\hline Pharmacologic & $17(24)$ & $15(32)$ & $2(9)$ & 0.03 \\
\hline Contingency management & $0(0)$ & $0(0)$ & $0(0)$ & - \\
\hline \multicolumn{5}{|l|}{ MOUD treatment } \\
\hline Methadone & $36(51)$ & $21(44)$ & $15(65)$ & 0.09 \\
\hline Buprenorphine & $66(93)$ & $45(94)$ & $21(91)$ & 0.71 \\
\hline Naltrexone & $11(15)$ & $11(23)$ & $0(0)$ & 0.01 \\
\hline No MOUD & $6(8)$ & $4(8)$ & $2(9)$ & 0.96 \\
\hline Current MOUD & $59(83)$ & $41(85)$ & $18(78)$ & 0.45 \\
\hline \multicolumn{5}{|l|}{ Prescription history } \\
\hline Opioid & $13(18)$ & $8(17)$ & $5(22)$ & 0.61 \\
\hline Stimulant & $35(49)$ & $24(20)$ & $11(48)$ & 0.86 \\
\hline Benzodiazepine & $24(34)$ & $16(33)$ & $8(35)$ & 0.90 \\
\hline Medical marijuana & $3(4)$ & $1(2)$ & $2(9)$ & 0.2 \\
\hline History of naloxone prescription & $60(85)$ & $42(88)$ & $18(78)$ & 0.31 \\
\hline History of PrEP treatment & $20(28)$ & $16(33)$ & $4(17)$ & 0.16 \\
\hline \multicolumn{5}{|l|}{ Addiction specialty services } \\
\hline Addiction consult team & $49(69)$ & $36(75)$ & $13(57)$ & 0.11 \\
\hline Bridge clinic & $57(80)$ & $41(85)$ & $16(70)$ & 0.11 \\
\hline West end clinic & $23(32)$ & $14(29)$ & $9(39)$ & 0.40 \\
\hline Addiction psychiatry & $43(61)$ & $31(65)$ & $12(52)$ & 0.32 \\
\hline Buprenorphine-prescribing PCP & $18(25)$ & $11(23)$ & $7(30)$ & 0.50 \\
\hline OBAT RN & $20(28)$ & $15(31)$ & $5(22)$ & 0.4 \\
\hline Recovery coach/peer support & $56(79)$ & $40(83)$ & $16(70)$ & 0.18 \\
\hline Other & $2(3)$ & $1(2)$ & $1(4)$ & 0.59 \\
\hline \multicolumn{5}{|l|}{ Drug use behaviors } \\
\hline \multicolumn{5}{|l|}{ Drug use } \\
\hline Fentanyl & $59(84)$ & $44(94)$ & $15(65)$ & $<0.01$ \\
\hline Cannabis & $64(90)$ & $45(94)$ & $19(83)$ & 0.14 \\
\hline Alcohol & $64(90)$ & $46(96)$ & $18(78)$ & 0.02 \\
\hline Tobacco & $66(93)$ & $45(94)$ & $21(91)$ & 0.71 \\
\hline Injection drug use & $65(92)$ & $48(100)$ & $17(74)$ & $<0.01$ \\
\hline \multicolumn{5}{|l|}{ Route of methamphetamine use } \\
\hline Injection & $48(68)$ & - & - & - \\
\hline Smoking & $22(31)$ & $15(31)$ & $7(30)$ & 0.95 \\
\hline Snorting & $18(25)$ & $13(27)$ & $5(22)$ & 0.63 \\
\hline Other & $2(3)$ & $1(2)$ & $1(4)$ & 0.59 \\
\hline \multicolumn{5}{|l|}{ High risk behaviors } \\
\hline None & $39(55)$ & $21(44)$ & $18(78)$ & $<0.01$ \\
\hline Sex work & $9(13)$ & $9(19)$ & $0(0)$ & 0.03 \\
\hline Needle sharing & $28(39)$ & $26(54)$ & $2(9)$ & $<0.01$ \\
\hline Other & $0(0)$ & $0(0)$ & $0(0)$ & _- \\
\hline
\end{tabular}

Bolded rows are significantly different, $\mathrm{p}<0.05$

Significant $\mathrm{p}$ value $=0.5$. Pharmacologic MUD treatment includes bupropion, naltrexone, rivastigmine, topiramate, modafinil, mirtazapine, or stimulant medications MOUD medications for opioid use disorder; MUD methamphetamine use disorder; PrEP pre-exposure prophylaxis; OBAT RN office-based addiction treatment nurse

\section{Addiction care and treatment engagement}

Most participants had received a prescription for naloxone $(85 \%)$ and were currently on medication for opioid use disorder (83\%) (MOUD). Nearly all participants (93\%) had ever been treated with buprenorphine, with smaller proportions having ever been treated with methadone (51\%), or naltrexone (15\%) as MOUD. A sizable minority of participants had received recent prescriptions for stimulants (49\%), benzodiazepines (34\%), and opioid pain medications (18\%), and $4 \%$ used medical cannabis 
via a certification in 2019 or 2020 . Only $24 \%$ had documentation of pharmacologic treatment explicitly for their MUD, and none had received contingency management behavioral treatment. Only $28 \%$ received pre-exposure prophylaxis (PrEP) prescriptions to prevent HIV acquisition. Of those who received PrEP prescriptions, $40 \%$ were only given one-time prescriptions. A large proportion of individuals accessed addiction specialty services, such as a low-barrier-to-entry bridge clinic (80\%), peer-support recovery coaching (79\%), consultation from our academic medical center's addiction consult team (69\%), and addiction psychiatry (61\%). A smaller proportion received care from a registered nurse providing office-based addiction treatment (OBAT RN) (28\%) or had a buprenorphineprescribing PCP (25\%).

\section{Drug use behaviors}

Most individuals reported a history of using fentanyl (84\%), cannabis (90\%), alcohol (90\%), and tobacco (93\%). Nearly all reported injection use of any substance (92\%) and some reported sharing needles at least once (39\%). In our cohort, 13\% reported engaging in sex work. Participants endorsed using methamphetamines via injection (68\%), smoking (31\%), and snorting (25\%).

\section{Characteristics stratified by route of methamphetamine use}

We compared the characteristics of individuals who inject methamphetamine with the characteristics of individuals who used methamphetamine by all other non-injection routes. Individuals who inject methamphetamine were significantly more likely to have a stimulant $(98 \%$ vs. $78 \% ; \mathrm{p}=0.01)$ and benzodiazepine use disorder $(52 \%$ vs. $17 \% ; \mathrm{p}=0.01)$ diagnosis compared to individuals who reported using methamphetamine exclusively via other routes. They were more likely to have a history of drug overdose ( $91 \%$ vs. $70 \% ; \mathrm{p}=0.02)$, have HCV $(94 \%$ vs. $52 \%$; $\mathrm{p}<0.01)$ or superficial abscesses $(75 \%$ vs. $52 \% ; \mathrm{p}=0.05)$, use fentanyl $(93 \%$ vs. $65 \% ; \mathrm{p}=0.02)$, use alcohol $(96 \%$ vs. $78 \% ; p=0.02)$, share needles $(54 \%$ vs. $9 \% ; \mathrm{p}<0.01)$ and engage in sex work $(19 \%$ vs. $0 \%$; $\mathrm{p}=0.03)$. Those who inject methamphetamine were more likely to have received MUD pharmacologic treatment $(32 \%$ vs. $9 \% ; \mathrm{p}=0.03)$ and naltrexone prescriptions $(23 \%$ vs. $0 \% ; \mathrm{p}=0.01)$.

No significant sociodemographic differences were found between these groups. Both had prevalent experiences of homelessness ( $88 \%$ vs. $73 \%$; $p=0.15)$ and incarceration $(81 \%$ vs. $64 \% ; \mathrm{p}=0.11)$, depression $(94 \%$ vs. $87 \% ; \mathrm{p}=0.34)$, suicidal attempt/ideation $(56 \%$ vs. $61 \%$; $\mathrm{p}=0.71)$, psychosis $(49 \%$ vs. $30 \% ; \mathrm{p}=0.14)$ and serious infections, including bacteremia ( $27 \%$ vs. $22 \%$; $=0.63)$, endocarditis $(19 \%$ vs. $4 \% ; \mathrm{p}=0.10)$, and osteomyelitis $(13 \%$ vs. $9 \% ; \mathrm{p}=0.64)$.

\section{Discussion}

This retrospective cohort study is among the first to characterize outpatient care-engaged individuals who use methamphetamine at a large, urban academic center in the Northeast US, revealing a clinically and socially complex population with high prevalence of polysubstance use, intravenous drug use, psychiatric comorbidities, infectious complications, overdose, homelessness, and incarceration. Participants who reported injecting methamphetamine faced further risks, with a higher prevalence of drug overdose, HCV infection, fentanyl use, and sex work. Overall, we found a similarly elevated prevalence of adverse social determinants of health between people who used methamphetamine via injection versus other routes. Our cohort reflected characteristics previously associated with greater risk for MUD: male sex; limited college education; concomitant tobacco, cannabis, sedative use; and co-occurring mental illness. Notably, our study participants faced significant sociodemographic challenges and clinical complications similar to those noted in nationwide cohorts, despite their engagement in outpatient and specialty addiction care $[21,32]$.

Our cohort was notable for a high prevalence of polysubstance use, particularly co-occurring OUD and MUD in over $90 \%$ of participants. While nearly all participants were treated for their OUD with gold-standard MOUD, none of the $78 \%$ with documented stimulant use disorder had documented discussions of or referrals to the most effective evidence-based behavioral treatment for stimulant use disorder: contingency management [24-26, 33]. Although $24 \%$ of participants received some form of pharmacologic treatment for their MUD, all were prescribed for off-label use. While half of the participants in the study had received a stimulant prescription in the past year, the indication for the prescription was not always clear and may have included methamphetamine use harm reduction, attention deficit and hyperactivity disorder treatment, or other reasons. While there have been many medical trials involving participants with OUD, only one involved participants with comorbid OUD and MUD; the lack of medication trials in this growing population highlights an urgent need for further research [34].

Clinical trials have shown promising effects from stimulant agonist treatment (dexamphetamine or methylphenidate), mirtazapine, and combination bupropion and extended-release injectable naltrexone therapy, but these medications do not currently have FDA approval $[22,23$, 
35, 36]. Additionally, the modest effect of bupropion and extended-release naltrexone requires a prolonged period of opioid abstinence, which may be a barrier in a population of people with MUD and high likelihood of comorbid OUD.

Taken together, our results suggest the need to screen care-engaged individuals with methamphetamine use for concomitant OUD, and vice versa, and highlight that contingency management is an underutilized treatment in this population. Despite its strong evidence base, contingency management is the least commonly delivered behavioral intervention for substance use disorders, owing to philosophical and durability concerns amongst providers and economic challenges with limited CM reimbursement through insurance [28]. Given the extremely limited availability of CM treatment across the US, rapid development and implementation of such programs is necessary [33]. The Veterans Administration's highly successful nationwide implementation of $\mathrm{CM}$ across all its outpatient substance use treatment clinics serves as a model for integrating $\mathrm{CM}$ into addiction care [37].

Moreover, in the context of limited available treatment options for MUD and the high prevalence of polysubstance use, evidence-based harm reduction practices that reduce mortality and morbidity across all types of substance use is critical. Individuals who use injection methamphetamine may particularly benefit from increased access to naloxone, fentanyl test strips, safer sex kits and sterile injection supplies, given their higher prevalence of overdose, Hepatitis $\mathrm{C}$ virus ( $\mathrm{HCV}$ ), and engagement in high-risk sex practices. Additionally, nearly half of the participants who received PrEP were not continued longterm on preventative HIV treatment. Due to increased HIV prevalence, sex work, and injection practices among people who use drugs in Massachusetts, providing maintenance PrEP prescriptions coupled with routine sexually transmitted infection testing is a critical step in mitigating HIV spread [38]. To address the multifaceted needs of individuals with SUDs, co-located multidisciplinary care systems providing SUD treatment, infectious disease care, behavioral treatment, and harm reduction resources have been developed in primary care, Human Immunodeficiency Virus (HIV) specialty care, opioid treatment program, and transitions clinic settings [39]. Inclusion of $\mathrm{CM}$ would be appropriately placed within the context of other models of integrated addiction care. Finally, the high prevalence of homelessness and incarceration, despite relatively strong treatment engagement, highlight the need for affordable housing and drug law reform alongside any clinical or public health intervention.

This study must be viewed in light of its limitations. First, the study-which included a predominantly white and care-engaged participant population-was conducted at a single large urban academic health center and may not be generalizable to a wider population. Second, the relatively small sample size provides limited power to capture statistically significant differences between participants who inject methamphetamine versus use by other routes. Third, this was a retrospective study conducted by EMR review and answers to certain questions (for example, route of drug use) are limited by documentation variability and participants' social desirability biases. With regards to the self-reported route of use, we believe the result would be biased towards no difference between the groups and may reflect an underestimate of individuals who inject methamphetamine. Additionally, because this study relied on retrospective EMR review and healthcare provider documentation, we were limited in our ability to capture care outside our medical system and accurately account for individuals' self-identified gender and sexual orientations in our analyses. Prospective studies of people who use methamphetamine, coupled with explanatory qualitative interviews, are warranted.

\section{Conclusions}

Individuals in our study had high prevalence of polysubstance use, particularly concomitant methamphetamine and opioid use. Our findings are concordant with findings from nationwide cohorts demonstrating significant sociodemographic challenges and clinical complications among individuals who use methamphetamine. Individuals who are well connected to substance use treatment for their OUD are still likely to be undertreated for their MUD and would benefit from greater access to contingency management treatment, harm reduction resources, and resources to address adverse social determinants of health.

\section{Acknowledgements \\ The authors would like to acknowledge Dr. Dinah Puchner Applewhite, who provided clinical feedback on and an expert review of the manuscript. \\ Authors' contributions \\ $\mathrm{BB}, \mathrm{JM}$, and GA conceived the study question. BB and JM contributed to the development of the chart review instrument and developed the search strategy. BB, JM, MYL extracted data. MYL performed statistical analysis. BB, JM, MYL participated in the resolution of discrepancies during data extraction. All authors read and approved the final manuscript.}

\section{Funding}

This study was supported by NIH/NIDA under Grant Number K12DA043490 (BB).

\section{Availability of data and materials}

All data generated and datasets used during the current study will be available from the corresponding author on reasonable request. 


\section{Declarations}

\section{Ethics approval and consent to participate}

Ethical approval was provided by the Partners Massachusetts General Brigham IRB Committee.

\section{Consent for publication}

Not applicable.

\section{Competing interests}

The authors declare that they have no competing interests.

\begin{abstract}
Author details
'Harvard Medical School, 25 Shattuck St, Boston, MA 02115, United States. ${ }^{2}$ CommonSpirit Heath Enterprise Population Health, 185 Berry Street, Suite 200, San Francisco, CA 94107, United States. ${ }^{3}$ Department of Medicine, Massachusetts General Hospital, 100 Cambridge Street, Suite 1600, Boston, MA 02114, United States.
\end{abstract}

Received: 19 April 2021 Accepted: 14 September 2021

Published online: 26 September 2021

\section{References}

1. Ellis MS, Kasper ZA, Cicero TJ. Twin epidemics: the surging rise of methamphetamine use in chronic opioid users. Drug Alcohol Depend. 2018;193:14-20.

2. Ciccarone D. The triple wave epidemic: supply and demand drivers of the US opioid overdose crisis. Int J Drug Policy. 2019;71:183-8.

3. Fogger SA. Methamphetamine use. A New wave in the opioid crisis? J Addict Nurs. 2019;30(3):219-23.

4. Winkelman TNA, Admon LK, Jennings L, Shippee ND, Richardson CR, Bart G. Evaluation of amphetamine-related hospitalizations and associated clinical outcomes and costs in the United States. JAMA Netw Open. 2018;1(6):e183758-e183758.

5. Capizzi J, Leahy J, Wheelock H, Garcia J, Strnad L, Sikka M, et al. Population-based trends in hospitalizations due to injection drug userelated serious bacterial infections, Oregon, 2008 to 2018. PLOS ONE. 2020;9(11):e0242165.

6. Hedegaard H, Bastian BA, Trinidad JP, Spencer M, Warner M. Drugs most frequently involved in drug overdose deaths: United States, 2011-2016. Natl Vital Stat Rep Cent Dis Control Prev Natl Cent Health Stat Natl Vital Stat Syst. 2018;67(9):1-14

7. The Lancet. Opioids and methamphetamine: a tale of two crises. Lance Lond Engl. 2018;24(10122):713.

8. Wakeman S, Flood J, Ciccarone D. Rise in presence of methamphetamine in oral fluid toxicology tests among outpatients in a large healthcare setting in the Northeast. J Addict Med. 2020. https://doi.org/10.1097/ADM. 0000000000000695

9. Barocas JA, Wang J, Marshall BDL, LaRochelle MR, Bettano A, Bernson D, et al. Sociodemographic factors and social determinants associated with toxicology confirmed polysubstance opioid-related deaths. Drug Alcohol Depend. 2019;01:59-63.

10. Hedegaard H, Bastian BA, Trinidad JP, Spencer MR, Warner M. Regional differences in the drugs most frequently involved in drug overdose deaths: United States. Natl Vital Stat Rep. 2017;68(12):16.

11. Jalal H, Buchanich JM, Roberts MS, Balmert LC, Zhang K, Burke DS. Changing dynamics of the drug overdose epidemic in the United States from 1979 through 2016. Science. 2018;21(6408):361.

12. Jones CM, Underwood N, Compton WM. Increases in methamphetamine use among heroin treatment admissions in the United States, 2008-17. Addiction. 2020;115(2):347-53.

13. Tsui JI, Mayfield J, Speaker EC, Yakup S, Ries R, Funai H, et al. Association between methamphetamine use and retention among patients with opioid use disorders treated with buprenorphine. J Subst Abuse Treat 2020;1:80-5.

14. Mattson CL. Trends and geographic patterns in drug and synthetic opioid overdose deaths_United States, 2013-2019. MMWR Morb Mortal Wkly Rep. 2021. https://doi.org/10.15585/mmwr.mm7006a4.
15. Chawarski MC, Hawk K, Edelman EJ, O'Connor P Owens P Martel S, et al. Use of amphetamine-type stimulants among emergency department patients with untreated opioid use disorder. Ann Emerg Med. 2020;76(6):782-7

16. McKetin R, Ross J, Kelly E, Baker A, Lee N, Lubman DI, et al. Characteristics and harms associated with injecting versus smoking methamphetamine among methamphetamine treatment entrants. Drug Alcohol Rev. 2008;27(3):277-85.

17. Levitt A, Mermin J, Jones CM, See I, Butler JC. Infectious diseases and injection drug use: public health burden and response. J Infect Dis. 2020;222(Supplement_5):S213-7.

18. Neils M, McQuade E, Scheld W, Dillingham R. Rising rates of injection drug use associated infective endocarditis in Virginia with missed opportunities for addiction treatment referral: a retrospective cohort study. BMC Infect Dis. 2018. https://doi.org/10.1186/s12879-018-3408-y.

19. Iritani BJ, Hallfors DD, Bauer DJ. Crystal methamphetamine use among young adults in the USA. Addict Abingdon Engl. 2007;102(7):1102-13.

20. Marshall BDL, Wood E, Shoveller JA, Buxton JA, Montaner JSG, Kerr T, Individual. Social and environmental factors associated with initiating methamphetamine injection: implications for drug use and HIV prevention strategies. Prev Sci Off J Soc Prev Res. 2011;12(2):173-80.

21. Jones CM. Patterns and characteristics of methamphetamine use among adults-United States, 2015-2018. MMWR Morb Mortal Wkly Rep. 2020 https://doi.org/10.15585/mmwr.mm6912a1.

22. Siefried KJ, Acheson LS, Lintzeris N, Ezard N. Pharmacological treatment of methamphetamine/amphetamine dependence: a systematic review. CNS Drugs. 2020;34(4):337-65.

23. Chan B, Freeman M, Kondo K, Ayers C, Montgomery J, Paynter R, et al. Pharmacotherapy for methamphetamine/amphetamine use disorder-a systematic review and meta-analysis. Addiction. 2019;114(12):2122-36.

24. McPherson SM, Burduli E, Smith CL, Herron J, Oluwoye O, Hirchak K, et al. A review of contingency management for the treatment of substanceuse disorders: adaptation for underserved populations, use of experimental technologies, and personalized optimization strategies. Subst Abuse Rehabil. 2018:9:43-57.

25. Brown HD, DeFulio A. Contingency management for the treatment of methamphetamine use disorder: a systematic review. Drug Alcohol Depend. 2020;1:108307.

26. Higgins ST, Silverman K, Heil SH. Contingency management in substance abuse treatment. New York: The Guilford Press; 2007. p. 380.

27. Bolívar HA, Klemperer EM, Coleman SRM, DeSarno M, Skelly JM, Higgins ST. Contingency management for patients receiving medication for opioid use disorder: a systematic review and meta-analysis. JAMA Psychiatry. 2021. https://doi.org/10.1001/jamapsychiatry.2021.1969.

28. Petry NM, Alessi SM, Olmstead TA, Rash CJ, Zajac K. Contingency management treatment for substance use disorders: how far has it come, and where does it need to go? Psychol Addict Behav J Soc Psychol Addict Behav. 2017;31(8):897-906.

29. Borg D, Kolb E, Lantigua C, Stripp R. Chiral analysis of methamphetamine in oral fluid samples: a method to distinguish licit from illicit drug use. J Anal Toxicol. 2018;42(1):25-32.

30. Crooks CR, Brown S, Roche DAT, Immunoassay. Sensitivity and specificity testing for amphetamines, cocaine, and opiates in oral fluid. J Anal Toxicol. 2010;34(1):103-9

31. Harris PA, Taylor R, Thielke R, Payne J, Gonzalez N, Conde JG. Research electronic data capture (REDCap) — a metadata-driven methodology and workflow process for providing translational research informatics support. J Biomed Inform. 2009:42(2):377-81.

32. Substance Abuse and Mental Health Services Administration. Results from the 2018 National Survey on Drug Use and Health. US Department of Health and Human Services, Substance Abuse and Mental Health Services Administration. 2019. https://www.samhsa.gov/data/report/ 2018-nsduh-detailed-tables. Accessed 11 Feb 2021.

33. Glass JE, Nunes EV, Bradley KA. contingency management. A highly effective treatment for substance use disorders and the legal barriers that stand in its way. JAMA Netw Open. 2021. https://doi.org/10.1377/hblog 20200305.965186/full/.

34. Chan B, Freeman M, Ayers C, Korthuis PT, Paynter R, Kondo K, et al. A systematic review and meta-analysis of medications for stimulant use 
disorders in patients with co-occurring opioid use disorders. Drug Alcohol Depend. 2020;1:108193.

35. Trivedi MH, Walker R, Ling W, dela Cruz A, Sharma G, Carmody T, et al. Bupropion and naltrexone in methamphetamine use disorder. N Engl J Med. 2021;14(2):140-53.

36. Coffin PO, Santos G-M, Hern J, Vittinghoff E, Walker JE, Matheson T, et al. Effects of mirtazapine for methamphetamine use disorder among cisgender men and transgender women who have sex with men: a placebocontrolled randomized clinical trial. JAMA Psychiatry. 2020:77(3):246-55.

37. Petry NM, DePhilippis D, Rash CJ, Drapkin M, McKay JR. Nationwide dissemination of contingency management: the Veterans Administration initiative. Am J Addict Am Acad Psychiatr Alcohol Addict. 2014:23(3):205-10.
38. Alpren C, Dawson EL, John B, Cranston K, Panneer N, Fukuda HD, et al. Opioid use fueling HIV transmission in an urban setting: an outbreak of HIV infection among people who inject drugs-Massachusetts, 2015-2018. Am J Public Health. 2020;1 10(1):37-44.

39. Rich KM, Bia J, Altice FL, Feinberg J. Integrated models of care for individuals with opioid use disorder: how do we prevent HIV and HCV? Curr HIV/AIDS Rep. 2018;15(3):266-75.

\section{Publisher's Note}

Springer Nature remains neutral with regard to jurisdictional claims in published maps and institutional affiliations.
Ready to submit your research? Choose BMC and benefit from:

- fast, convenient online submission

- thorough peer review by experienced researchers in your field

- rapid publication on acceptance

- support for research data, including large and complex data types

- gold Open Access which fosters wider collaboration and increased citations

- maximum visibility for your research: over 100M website views per year

At BMC, research is always in progress.

Learn more biomedcentral.com/submissions 